\title{
ESPIRITUALIDAD DE LOS SENTIDOS EN LOS RELATOS DE LA CIUDAD
}

\author{
Spirituality of the senses in the stories of the city
}

Juan Pablo Espinosa Arce ${ }^{\mathrm{I}}$

\section{Resumen}

La espiritualidad es una cualidad propia del ser humano. A través de ella vamos realizando un recorrido con Dios, en quien reconocemos el sentido profundo de nuestras vidas. La vida humana, espacio de encuentro con Dios, se comprende como la vinculación de cuerpo y espíritu, de la dimensión personal y comunitaria, de la vivencia hogareña y urbana. A partir de esta consideración, este artículo busca adentrarse en la categoría y tema de la "espiritualidad de los sentidos", la cual ha sido propuesta y desarrollada por el teólogo portugués José Tolentino Mendonça. Los sentidos son definidos como puertas de acceso a la realidad, a la historia, al mundo y a los otros. Por medio de los sentidos, del cuerpo y de nuestra interioridad, vamos desarrollando la vida, vida caminada, celebrada, originada y finalizada en medio de nuestras ciudades. Surge, por tanto, la consideración de pensar cómo en medio de la ciudad, de las tramas urbanas, de los desafíos de convivencia actual, ejercitamos la mencionada espiritualidad de los sentidos.

\section{Palabras clave:}

Antropología teológica; Olfato; Espiritualidad; Mística; Instante.

\section{Abstract}

Spirituality is a quality of the human being. Through it we go on a journey with God, in whom we recognize the deep meaning of our lives. Human life, a space of encounter with God, is understood as the link between body and spirit, of the personal and the community dimension, of the home and urban experience. Based on

1 Magíster en Teología Fundamental por la Pontificia Universidad Católica de Chile. Profesor en la Pontificia Universidad Católica de Chile y en la Universidad Alberto Hurtado. Correo electrónico: jpespinosa@uc.cl 
this consideration, this article seeks to delve into the category and topic of "spirituality of the senses", which has been proposed and developed by the Portuguese theologian José Tolentino Mendonça. The senses are defined as access doors to reality, to history, to the world and to others. Through the senses, the body and our interiority, we develop life, a life walked, celebrated, originated and ended in the middle of our cities. Therefore, the consideration arises of thinking how in the middle of the city, of the urban fabric, and of the challenges of current coexistence, we exercise the aforementioned spirituality of the senses.

\section{Keywords:}

Theological Anthropology; Smell; Spirituality; Mystique; Instant.

\section{Introducción}

La tesis que buscamos proponer en este trabajo tiene que ver con recuperar la propuesta de la espiritualidad de los sentidos del teólogo portugués José Tolentino Mendonça. Los sentidos, como espacio de vivir el seguimiento de Jesús de Nazaret, eso es la espiritualidad, se realiza en medio de los relatos humanos, de las experiencias y de las búsquedas cotidianas de sentido personal, comunitario y de vinculación de Dios. En particular, este artículo, en tanto ha sido pensado y compuesto desde la ciudad y sus complejos dinamismos, tendrá el carácter de pensar la espiritualidad de los sentidos en los relatos de la ciudad. Por esta categoría estaremos comprendiendo que el transitar humano posee narrativas, experiencias que se comunican, cuerpos que se interrelacionan, vinculaciones con el pasado, experiencias de presente y sueños de futuro. Ahora, el adjetivo de la ciudad no es excluyente a otros espacios humanos, sino que más bien indica el lugar desde el cual se piensa y construye esta propuesta. Y, finalmente, indicar que el marco general es doble, a saber: la experiencia de la pandemia del coronavirus como momento de época que ha supuesto una reimaginación de las mismas experiencias humanas, políticas, económicas y también espirituales o religiosas y, en segundo lugar, el marco de la antropología teológica como cuestión teológica particular que consideramos relevante al pensar la espiritualidad, en razón de que ella, la espiritualidad, es una experiencia humana tanto en su forma de comprensión como en su práctica cotidiana, que, en nuestro caso, tiene que ver con los sentidos, el cuerpo y los modos de transitar el espacio cotidiano.

\section{La antropología teológica en tanto marco referencial de la propuesta}

Por tanto, si el tema que buscamos proponer tiene que ver con la antropología teológica, consideramos ofrecer algunas caracterizaciones sobre esta área del pensamiento teológico. Al decir de Gelabert (2006), "es la reflexión sobre el ser humano a la luz del discurso sobre Dios [...] la antropología teológica es un discurso sobre el hombre a la luz del discurso sobre el Dios revelado en Cristo. Dicho de forma más 
sencilla y directa: antropología teológica es la visión cristiana del hombre" (p. 11). ${ }^{2}$ Este discurso sobre el hombre-mujer (la antropología), discurso pensado y comunicado desde la revelación que Dios realiza sobre sí mismo en la historia, y de un modo particular y definitivo en Jesús de Nazaret (cf. Jn 1, 14; Heb 1, 1-2), debe considerar la cultura en la cual encuentra su situación comunicativa. Lo anterior expresa que el conocimiento que poseemos de lo humano, conocimiento que nos viene de la revelación de Dios, debe encontrar en la cultura los modos de comunicación (lenguaje, símbolos, expresiones e imágenes).

Con ello, el conocimiento manifiesta dos aspectos íntimamente unidos entre sí: en primer lugar, indica que el conocimiento es situado, es decir, se piensa y se comunica en una historia particular, en un momento o época específica, en una situación particular y con coordenadas propias. El conocimiento tiene el carácter de ser histórico y situado porque el mismo ser humano es un ser situado, un ser lanzado a la historia. En segundo lugar, el conocimiento situado es limitado en tanto el enfoque que cada uno observa e intenta comprender responde a una experiencia particular propia. Es relativo en tanto no conocemos la totalidad de las cosas, sino que poseemos un determinado enfoque de visión.

Este elemento es recuperado por autores como Benzo (1978), quien indica:

Cada generación humana se encuentra con una situación cultural (social, económica, científica, técnica, política) caracterizada por unas determinadas adquisiciones y preocupaciones intelectuales propias, a la que a su vez modifica en su intento de superarlas y darles respuestas, y transmite, así transformadas, a la generación siguiente. La teología comparte, claro es, ese condicionamiento cultural con las otras disciplinas del saber. No solo porque el teólogo no puede evadirse de la época en que le ha correspondido vivir, sino porque no debe, ya que esas preocupaciones y adquisiciones particulares de su tiempo expresan aquellos aspectos de la eterna e inagotable pregunta por la verdad que más apasiona a sus contemporáneos, y a los que la teología, como los otros saberes, está obligada al intento de iluminar. (p. 34)

Desde lo anterior, podemos reconocer los siguientes elementos que, a nuestro entender, representan puntos de anclaje al pensar nuestro tema particular, a saber: la espiritualidad de los sentidos en los relatos de la ciudad.

En primer lugar, la consideración de la situación cultural en la que vivimos. Si nuestro tema tiene que ver con los sentidos, en tanto expresión de aquellas puertas de acceso que el ser humano cuerpo posee hacia la realidad, hemos de considerar que el cuerpo de nuestro tiempo tiene sus particularidades. Vivimos en la época del cuerpo pandémico, del cuerpo cubierto y protegido por mascarillas. Es el tiempo del cuerpo en cuarentena, del cuerpo contagiado y muerto por el contagio, ${ }^{3}$ del cuerpo que debió (y debe) habituarse a cambiar sus modos de vivir ese mismo cuerpo. Incluso, es muy sugerente pensar cómo han

2 Silva (1985), a propósito de la categoría “antropología teológica" (que la diferencia de "antropología cristiana”), indica que la primera "pretende sistematizar lo que encontramos en la revelación acerca del hombre, lo que es Palabra de Dios acerca del hombre, es decir, lo que podemos llamar 'el hombre según Dios'. Evidentemente, se trata de la Palabra revelada, una vez discerniendo su vehículo cultural y, por lo tanto, traducida a nuestra cultura” (p. 2).

3 A comienzos de la pandemia en 2020, ofrecí la reflexión "Las paradojas de la muerte en cuarentena" (18 de mayo 20202), la cual buscó ofrecer una primera reflexión en torno a qué significaba ser testigos de la muerte en el tiempo pandémico (Espinosa, 2020). 
sido nuestros sentidos las claves para detectar si estamos o no contagiados, en tanto se pierde el sentido del olfato y del gusto como síntomas de la misma pandemia. ${ }^{4} \mathrm{Al}$ decir de autores como Žižek (2021) en su obra sobre la pandemia de la covid-19, es necesario reconocer cómo el no me toques es una de las expresiones antropológicas fundamentales de este tiempo de contagios corporales.

Hoy, en medio de la epidemia del coronavirus, todos estamos bombardeados precisamente por llamadas a no tocar a los demás sino para aislarnos, para mantener una distancia corporal adecuada. ¿Qué significa el mandato "no me toques"? Las manos no pueden llegar a la otra persona; solo desde el interior podemos acercarnos los unos a los otros, y la ventana hacia "dentro" son nuestros ojos. En estos días, cuando conoces a alguien cercano (o incluso un extraño) y mantienes una distancia adecuada, una mirada profunda a los ojos del otro puede revelar más que un íntimo roce. (p. 11)

Estas pueden ser algunas claves desde las cuales vamos comprendiendo a qué hacemos referencia con el cuerpo, tanto en un nivel especulativo o categorial, pero también qué significa hacer experiencia corporal en nuestro tiempo pandémico. $Y$ en esto es necesaria la consideración de una nota importante: al hacer mención del "cuerpo", no estamos haciendo alusión de manera exclusiva a la carnalidad, sino expresando que toda la realidad humana es cuerpo. No solo tenemos cuerpo, sino que somos cuerpo. Hay una ontología corporal, una dimensión esencialmente corpórea de nuestra vida, lo cual es una nota que ya ha sido reconocida por varios autores. ${ }^{6}$ De este modo, es necesario pensar desde la teoría del conocimiento que el conocimiento-experiencia que tenemos de nuestro cuerpo es histórico (situado) y también limitado, es decir, cada uno de nosotros posee una particular comprensión del cuerpo en general y de su propio cuerpo (de la identidad particular) como comprensión específica. A través del cuerpo nos vinculamos con el mundo que nos circunda, hacemos la experiencia de las relaciones interpersonales, entramos en la capacidad del autoconocimiento, y podemos también vincularnos con lo trascendente. Con ello, el cuerpo es una realidad multidimensional.

4 Para profundizar en las razones médicas de la pérdida del olfato y del gusto, véase López (2020).

5 Žižek (2021) comienza su obra sobre la covid-19 con la cita joánica del capítulo 20, 17, la cual narra el encuentro entre Jesús resucitado y Magdalena. El Resucitado prohíbe ser tocado por la mujer, situación que es interpretada por Žižek en los siguientes términos: “¿Cómo puedo yo, un cristiano ateo declarado, entender estas palabras? Primero, las tomo junto con la respuesta de Cristo a la pregunta de su discípulo de cómo sabremos que ha regresado resucitado. Cristo dice que estará allí siempre. Cristo dice que estará allí siempre que haya amor entre sus creyentes. Estará allí no como una persona a quien tocar, sino como el vínculo de amor y solidaridad entre las personas, así que, no me toques, toca y trata con otros con el espíritu del amor" (p. 11).

6 Sesboüé (2000) indica que, "en realidad, no tenemos un cuerpo, sino que somos nuestro cuerpo" (p. 357). Y, en otro momento, sostiene que nuestro rostro, nuestras facciones, poseen una "belleza espiritual" y que son "lugares de experiencia espiritual” (p. 356). Lo último que Sesboüé señala es clave para el enfoque de nuestra propuesta: es el cuerpo donde hacemos la experiencia de la espiritualidad. Somos un cuerpo-espiritual, o un espíritu corporizado, o un cuerpo que se abre, desde el mismo cuerpo, a la experiencia de la espiritualidad. Nolan (2007) también recupera la consideración del cuerpo aplicado, en su caso, a la espiritualidad del encuentro con Jesús. Indica que el modo de amar a Jesús supone el amor a nuestro propio cuerpo y que abrazar la verdad de uno mismo es una "cuestión de humildad" (p. 196). También Amengual (2007) sostiene que, "cuando se ha caracterizado al hombre como ser-en-el-mundo, se plantea de inmediato la cuestión del cuerpo, dado que el estar en el mundo viene definido por el cuerpo. En efecto, es por mi cuerpo por lo que estoy presente en el mundo y me injiero en él [...] de este modo la corporalidad ha pasado a ser considerada como rasgo esencial del hombre" (p. 57). 
En segundo lugar, Benzo (1978) recuerda que la disciplina teológica ofrece una epistemología o un conocimiento particular. La teología es un posible enfoque para mirar la realidad. La teología, con ello, surge como una reflexión, un pensamiento que busca comprender la realidad (mundo, seres humanos, culturas, Dios-lo trascendente, la espiritualidad) desde un cuerpo categorial propio, reflexión que busca ser útil a la vida de la fe y a la discusión pública de esa fe con otros saberes. ${ }^{7} \mathrm{Y}$ dicha comprensión, como hemos indicado, es contextual y limitada. Por tanto, la teología como un pensamiento particular expresa que nunca podremos hacer experiencia total de la realidad, que, en sí misma, es multifocal.

En la teología, el foco desde el cual interpretamos la realidad es Cristo. El acontecimiento Cristo es el principio interpretativo (hermenéutico) por el cual comprendemos el cuerpo y los sentidos, como foco particular de nuestra propuesta. Si Benzo (1978) habla de la eterna e inagotable pregunta de la vida humana (el origen, la convivencia y el destino ${ }^{8}$ ), dicha pregunta se puede responder desde Cristo. Si la pregunta es qué es la espiritualidad de los sentidos en los relatos de la ciudad, la modulación de la respuesta pasa por la consideración de la Encarnación, es decir, de que Dios mismo en Jesús se hace cercano a nosotros en el cuerpo. Dios se apropió de nuestro cuerpo, de nuestra sensibilidad, de nuestra experiencia histórica y mundana $(J n$ 1, 14). Dios en Jesús ha asumido los cinco sentidos del cuerpo, el sentido común, la vinculación afectiva y cognitiva que vivimos a través de la corporalidad.

\section{Cuerpo, sentimientos e integralidad humana}

Canals (2002) señala lo siguiente: "aunque es cierto que la reflexión consciente o la razón guía del mundo del ser humano, esta condición no condice el hecho del rol que juegan los afectos y, en particular, la

7 Wicks (1998) indica que "se hace teología con la esperanza de que sus resultados puedan ser útiles a los creyentes gracias a la mejor comunicación del mensaje cristiano y sus derivaciones" (p. 157).

8 Bentué (1986) define al ser humano como "incógnita y búsqueda” (p. 25). Dentro de la incógnita y de la búsqueda, expone lo siguiente: “ ¿y cuál es esta vivencia básica que determina nuestra situación en el mundo? Es la que surge de la triple coordenada con la cual se teje nuestra existencia: muerte, vida y convivencia” (p. 25). Por su parte, Gesché (2010) también recupera la dimensión de intriga y de enigma de la existencia humana. Sostiene: "deseamos conocernos, sin duda, pero no somos totalmente transparentes a nosotros mismos. Acaso haya que comenzar por ahí para comprenderse bien. El ser es ese ser en perpetua búsqueda de su humanidad y del secreto que ella encubre. Cuestión que no tiene nada de académica. Es existencial" (p. 17). Y, en otro momento, expresa: "para ser hombre, todo ser humano, deberá aprender cada vez más a convivir con el enigma. Este no puede ser abolido: ni por la racionalidad, ni por la fe, ni por la afectividad, ni por la acción ni por la técnica” (p. 22). Lo que Gesché expresa en esta última intuición es lo que hemos venido expresando hasta ahora: que el enfoque siempre es particular. No es solo la fe, o solo la técnica o solo la razón las que pueden abarcar toda la realidad. Es importante reconocer el carácter limitado de nuestro conocimiento, la incertidumbre de la misma noción de saber. A propósito del carácter existencial de la pregunta por el ser humano indicado por Gesché, Boasso (1989) también recupera el carácter de pregunta propio de la vida humana. Señala: "preguntar sobre qué es el hombre no surge solamente de una inquietud científica, o de una admiración filosófica, ya que la pregunta sobre el hombre afecta directamente al mismo hombre que interroga, exponiéndolo a los sacudones de la discusión. El hombre se interroga sobre su propia esencia porque es esencialmente problemático para sí mismo, y tanto más problemático cuanto acontecimientos dolorosos y amenazantes se erizaban a su alrededor, hasta cuestionar el sentido mismo de la existencia humana" (p. 21). 
expresión de sentimientos y emociones. ${ }^{9}$ La razón pura puede ser hermosa pero fría como un témpano. Solo la calidez de los afectos es capaz de entibiarla e iluminarla como la luz del sol, a través de un prisma que genera un arcoíris de colores" (p. 144). Este tema, que posee en su centro la integralidad de lo humano, elemento que hemos venido proponiendo desde el comienzo de esta reflexión (teoría del conocimiento, lo situado y lo limitado), muestra la importancia de no reducir la experiencia humana a la sola razón formal (instrumental o técnica), sino que da espacio a los afectos, a los sentimientos y a las emociones, todos elementos que se manifiestan a través del cuerpo. Estas ideas también las ha expuesto Canals (2015) cuando habla de la "visión integral sobre el ser humano" (p. 41). Esta visión integral es aquella que comprende al ser humano como un todo. La espiritualidad de los sentidos que estamos recuperando es aquella capaz de asumir la totalidad de lo humano, para, desde esta consciencia, detectar los modos en los que la experiencia creyente se va desarrollando. No creemos al margen del cuerpo, de los sentidos o de los afectos, sino que vivimos nuestra espiritualidad corporal, sensitiva y afectadamente.

En otro momento de su argumentación, Canals (2015) indica: "a diferencia del libro, la taza y el café, que son sistemas cerrados, nosotros somos materia viva como sistemas abiertos al medio. Intercambiamos energía, materia e información. Hablamos, comemos, procreamos, nos movilizamos con nuestros propios medios, nos relacionamos emocionalmente con otros e intercambiamos energía termodinámicamente" (p. 44).$^{10}$ Desde esta consideración, se nos indica que somos seres altamente complejos, complejidad vivida en la apertura ontológica (esencial) que poseemos y desde la cual nos vamos desarrollando.

Es en medio de nuestra condición humana que se nos abre la posibilidad de la vinculación con lo trascendente. Organizamos y realizamos la búsqueda del sentido desde nuestra corporalidad, desde los sentidos y sentimientos, desde nuestras relaciones fundamentales. En tiempos de contagio, es sugerente recuperar cómo, incluso, en el cuerpo pandémico surge la pregunta por el lugar de la espiritualidad, por su inteligencia y por su carácter de experiencia. López (2019) indaga estas cuestiones cuando declara:

9 Recuperamos la propuesta de Nussbaum (2014) quien coloca en vínculo directo las emociones y la política. Recuperamos también el artículo de García (2017), el cual continúa la misma propuesta de la vinculación entre política y emociones. Considero que estas cuestiones deben continuar siendo asumidas por la teología de manera de ofrecer nuevas interlocuciones en los espacios públicos en los cuales se desarrolla como saber particular.

10 En este capítulo, Canals (2015) está recuperando también la propuesta que Humberto Maturana y Francisco Varela ofrecen en torno a la autopóiesis, es decir, a la consideración de que el ser humano junto con ser un organismo mismo es capaz de organizarse (de comprenderse) desde el reconocimiento de su interioridad. Vale la pena considerar cómo Maturana (2020) pone especiales acentos en la importancia de la emoción en el proceso de aprendizaje. Indica: "no hay acción humana sin una emoción que la funde como tal y la haga posible como acto. Para que un modo de vida basado en el estar juntos en interacciones recurrentes en el plano de la sensualidad se diese, se requeriría de una emoción fundadora particular, sin la cual ese modo de vida en la convivencia no sería posible. Tal emoción es el amor. El amor es la emoción que constituye el dominio de las acciones en el que nuestras interacciones recurrentes con otro hacen al otro un legítimo otro en la convivencia” (p. 39). La propuesta de Maturana es muy interesante de recuperar para pensar, por ejemplo, nuestra disciplina teológica. Él es consciente de que el proceso de aprendizaje que el ser humano realiza se entiende necesariamente desde las emociones que vive. Entonces, podríamos preguntarnos también cómo la experiencia religiosa involucra no solo un aspecto categorial, sino que supone el ejercicio de parte del sujeto creyente que vive su itinerario de encuentro con Dios. En dicho itinerario, se presentan emociones y sentimientos, los cuales debemos detectar, caracterizar y asumir como pasos en el mismo itinerario. Esto, pienso, es un trabajo que puede significar y dar como resultado una nueva reflexión. 
Mi cuerpo, ese espacio habitable. Su interior -el intracuerpo, para Ortega y Gasset-, también lo percibo. No lo agotan las sensaciones de nuestros órganos o de nuestros músculos/tendones, que nos informan de nuestra ubicación. Cierro mis ojos y siento [...] hasta desbordarnos y desembocar en un océano consciente que trasciende nuestros límites. (p. 79)

La habitabilidad del cuerpo supone el ejercicio de los sentidos que se abren y disponen a captar lo trascendente que está más allá de la carne, pero que supone su reconocimiento. Desde el cuerpo vamos abriendo nuestros sentidos a lo superior. Se ejerce la auténtica inteligencia espiritual, lo que, a juicio de Vaughan (2002) citado en Torralba (2019), tiene que ver con

la capacidad de comprender con profundidad las cuestiones existenciales de distintos niveles de consciencia [...] una persona espiritualmente inteligente tiene una enorme capacidad de conexión con todo lo que existe, pues es capaz de intuir los elementos que unen, lo que subyace en todos, lo que permanece, más allá de las individualidades. (p. 49)

La integralidad humana por la que estamos apostando supone el ejercicio de reconocer cómo la inteligencia no es solo la instrumental, sino que se adentra en los elementos de la espiritualidad, de los sentimientos y de las emociones. Lo que Canals $(2002,2015)$ y Torralba (2019) nos muestran con sus propuestas es que toda la vida representa una fuerza a través de la cual vamos viviendo la profundidad del vínculo con lo otro. Los sentidos, como puertas de acceso al mundo y como espacio de experiencia espiritual, nos abren la posibilidad de captar otras formas de vida, de una vida toda y compleja.

Por tanto, si nuestra propuesta busca indagar la espiritualidad de los sentidos en los relatos de la ciudad, el enfoque se articula en el cruce de la antropología teológica (tal y como la hemos venido comentando) y la cristología, es decir, cómo Jesucristo da un sentido transformador a nuestros cuerpos y a los sentidos de nuestro cuerpo (vista, gusto, tacto, olfato y oído). Nuestro cuerpo y Jesucristo están relacionados; nuestra forma de seguimiento de Jesús (la espiritualidad ${ }^{11}$ ) se realiza corporalmente y en el tránsito vivido en la ciudad y en sus relatos, es decir, en las diversas formas por medio de las cuales vamos comprendiendo el medio que nos rodea y comprendiéndonos a nosotros en la interacción con ese mismo medio. Por tanto, la espiritualidad en general y la espiritualidad de los sentidos en tanto enfoque particular poseen la característica fundamental de tener raíces antropológicas y de entender esta antropología como integral. ${ }^{12}$ Por tanto, la

11 Gamarra (2004) indica que "hay una gran coincidencia entre los autores en hacer resaltar que el objeto material es el común a toda teología: la existencia cristiana [...] el objeto de la teología espiritual es la vida cristiana no tanto en lo que ella es en sí, sino en cuanto que es asumida, apropiada y vivida por cada uno” (p. 14). La espiritualidad con ello es la forma concreta de la vida cristiana, del seguimiento de Jesús vivido en las modulaciones particulares de aquel que vive su seguimiento particular. Gamarra afirma más adelante que el método de la teología espiritual es inductivo y deductivo. Es inductivo en tanto tiene que ver con la experiencia espiritual de cada persona (casos particulares) y es deductivo en tanto ella, la teología espiritual, se entiende como cristiana, es decir, posee como criterio universal de interpretación el acontecimiento Cristo, y que, por ello, sostiene Gamarra, "deberá verse como antropología teológica” (p.15).

12 Gamarra (2004) indica que el punto de partida de la indagación sobre qué es la espiritualidad debe comenzar desde la antropología, desde unas raíces antropológicas, las cuales son tres: "el camino hacia el interior, el camino a lo trascendente y el camino hacia los otros" (p. 33). El camino hacia el interior o la interioridad es un elemento "esencial a la espiritualidad (y se la) considera el denominador común de toda espiritualidad y sirve de lazo de unión entre la espiritualidad cristiana y las no cristianas" (p. 34). El camino a lo trascendente significa, por su parte, el reconocimiento 
espiritualidad de los sentidos en medio de los relatos, de nuestras vidas particulares, familiares, eclesiales, políticas, económicas, culturales, pedagógicas, laborales, alimenticias, afectivas y eróticas, de oración y encuentro, es una forma de integrar el cuerpo en el encuentro con Cristo, de integrar la corporalidad en Aquel que ha querido compartir nuestra propia corporalidad (cf. Jn 1, 14).

\section{La espiritualidad de los sentidos o del instante: la propuesta de José Tolentino Mendonça}

Desde aquí ya comenzamos a presentar la propuesta de la espiritualidad de los sentidos de José Tolentino Mendonça. Lo primero es indicar que esta es una forma particular de comprender la espiritualidad y que, en cuanto a su aparato conceptual, metodología y elementos articuladores, es una forma dentro de un amplio concierto de formas de comprender la espiritualidad cristiana. Lo que nos llama la atención de esta propuesta y que buscamos relevar es el carácter poético, lúdico, sensible y actual de la espiritualidad de los santos, es decir, comprender cómo en el cuerpo hay una profunda espiritualidad. El modo de acercarnos a la propuesta de Mendonça será relevar algunos puntos centrales de su obra del mismo nombre (Hacia una espiritualidad de los sentidos) a modo de hermenéutica general de las mismas expresiones o elementos transversales, hermenéutica que se realizará, además, teniendo como foco los relatos de la ciudad que consideramos el posible espacio de interacción de esta espiritualidad sensible.

Para Mendonça (2016), el cuerpo y los elementos que lo manifiestan en los sentimientos, las emociones o los sentidos poseen una profunda dimensión espiritual. Es más, nos dice que "el cuerpo es la lengua materna de Dios" (p. 14). Es profundamente llamativo la gramática de lo materno, incluso, de lo femenino.

de la llamada actitud extática (o de salida) o de reconocimiento de un fundamento mayor de toda la realidad (lo sagrado, Dios, el Absoluto), el cual posee una dimensión de salvación de la misma humanidad. Finalmente, el camino hacia los otros es la tercera dimensión esencial de la espiritualidad. Por ella, comprendemos al ser humano como abierto a lo universal, como comprometido con ello, como aquel que trasciende las fronteras de su propio yo y se compromete con los demás, con la historia, con el mundo, con la creación. Podríamos encontrar en este triple camino lo que autores como Sánchez (2006) llama la "visión cósmica de la realidad”, la cual posee como clave de comprensión la capacidad de leer lo conocido y, desde eso conocido, ir descubriendo elementos nuevos (p.12). En otro momento, Sánchez indica que con esta visión cósmica de la realidad se busca "superar la concepción de la mística como mera experiencia íntima e individual, y apreciar su dimensión pública, su potencial conciliador y su virtualidad como elemento de cohesión social” (pp. 13-14). Por su parte, el autor que hemos escogido como caso particular de la espiritualidad de los sentidos, José Tolentino Mendoza, reconoce que su propuesta debe mantener la consideración de una "antropología más integradora" (Mendonça, 2016, p. 10). Por antropología integradora entendemos aquella que no considera que existe un principio positivo (el alma) y un principio negativo (cuerpo), sino que muestra una integración cuerpo-espíritu: somos cuerpo espiritual, espíritu encarnado. Y, en otro momento, Mendonça (2016), recordando a Thomas Merton, seńala que "la mística solo puede ser una experiencia cotidiana, solidaridad e integradora” (p. 11). Por otro lado, Watt (2006), y a propósito del desafío de educar la espiritualidad y la mirada integradora de la realidad (de la cual participa el cuerpo), indica: "considero que en la escuela, si se quiere ofrecer una educación integral, hay que educar la dimensión espiritual, so pena de atrofiar un aspecto fundamental de la persona. Igual que no basta saber historia del arte o de la música, sino que hay que desarrollar el sentido estético, artístico; igual que no es suficiente conocer las reglas de diferentes deportes, sino que hay que hacer ejercicio físico, para una formación integral no bastaría con tener conocimientos religiosos o sobre las religiones, sino que hay que cultivar la espiritualidad, hay que favorecer que se despierte y desarrolle la apertura a la trascendencia, a lo que desborda y engrandece los límites de la persona” (p. 86). 
Autores como Carl Jung desde la psicología han indicado que en el ser humano cohabita tanto el ánimo como el ánima, es decir, una dimensión más masculina y otra de carácter femenino. ${ }^{13}$ Nuevamente, vemos la integración de los aparentes contrarios, que, a su vez, supone el ejercicio de conocimiento y reconocimiento de cómo en nuestra experiencia vital cohabitan tanto lo divino como lo humano, lo masculino y lo femenino, el cuerpo y el alma. Esa es una clave importante al pensar la espiritualidad de los sentidos: todo lo que somos debe estar en la sintonía de la espiritualidad, es decir, la existencia cristiana total e integrada.

El sentido materno de la mística de los sentidos, de la espiritualidad del instante, es propuesto por Mendonça (2016) desde la imagen de un "laboratorio". Algo se ensaya, se practica, se busca; por ello, la metáfora del laboratorio. En este espacio de búsqueda, indica: "la vida es un laboratorio inmenso para la atención, la sensibilidad, el asombro que nos permite reconocer en cada instante, por escaso y precario que sea, la reverberación de una fantástica presencia: los pasos de Dios” (p. 14). Así, aparece una cuestión significativa, que surge como una propuesta clave: el laboratorio tiene la perspectiva de ser citadino. Es la espiritualidad de los sentidos en los relatos de la ciudad. Es aprender a captar el sentido de los pasos que en la ciudad vamos dando. Michel de Certeau, un autor al cual Mendonça (2016) recurre para proponer su obra de la espiritualidad de los sentidos, ${ }^{14}$ nos ha regalado un texto profundo, antropológico y sensible ante los tránsitos del caminar. Estamos haciendo referencia a La invención de lo cotidiano. En el volumen 1 de esta obra, De Certeau ha escrito el capítulo "Andares de la ciudad", el cual ofrece una interesante contraposición: por una parte, De Certeau (2007) ofrece el "concepto de ciudad” (p. 105), y por otra, las "prácticas urbanas" (p. 105).

El concepto de ciudad hace referencia a la planificación ideal que un arquitecto o un diseñador hace de un lugar y que proyecta en un plano o papel. A esta ciudad que llamaremos ideada, ¿qué le falta? Diremos y responderemos con De Certeau (2007) que su carencia está en las prácticas cotidianas que hacen que dicha ciudad tome vida, que sea un auténtico laboratorio. Un laboratorio solo es tal cuando los científicos lo habitan, lo pueblan, le dan sentido al espacio. Una cosa es la idea que tenemos de un laboratorio, pero otra muy distinta es el laboratorio vivido. Por ello, De Certeau (2007) ha dicho con razón que "la ciudad-

13 De Castro (2006) ofrece una buena introducción a la psicología de Jung. Señala: "este par de opuestos, como cualquier otro en la psicología junguiana, tiene una dinámica de integración que es de la mayor importancia para la madurez psicoafectiva de los individuos, sean hombres o mujeres" (p. 97). También indica que, culturalmente y desde la Antigüedad clásica grecorromana y cartesiana (primacía del cuerpo masculino y de la razón, o ánimo), se tendió a masculinizar toda la personalidad. Afirma: "vivimos en una era caracterizada por un fuerte racionalismo y por el contacto con el mundo a través del conocimiento intelectual y empírico, en desmedro del conocimiento intuitivo-afectivo [...] es decir, los aspectos femeninos de la vida poco han influido en el modo de vivir nuestra civilización” (p. 99). Canals (2002) aporta algunos elementos sugerentes en torno a esta misma discusión. Nos dice: "habitualmente utilizamos para instalarnos en la realidad el hemisferio izquierdo lineal, analítico y racional, en vez del hemisferio derecho capaz de establecer visiones alternativas de la realidad" (p. 35). En el ámbito teológico, destacamos el trabajo de María Clara Bingemer, el cual aborda la masculinidad y la feminidad como dos caras en el misterio de Jesucristo. Bingemer (2008) recupera, desde los arquetipos junguianos, la posibilidad de pensar la integración en Jesucristo, quien, en el acontecimiento de la Encarnación, asumió la vida humana masculina y femenina. Señala: "Dios no se hizo hombre y se identificó solo con la mitad de la humanidad, sino que se hizo carne, carne de hombre y de mujer, de forma que el camino hacia el Padre debe pasar necesariamente por la condición humana total, que es masculina y femenina [...] y solo ahí puede la teología, por fin, balbucear su palabra” (p. 388).

14 Es de importancia este autor en Mendonça (2016) hasta el punto de que el segundo comienza con un epígrafe certeauniano: "es místico aquel o aquella que no puede dejar de caminar" (p. 7). 
concepto se degrada" (p. 107), degradación que sufre porque la ciudad real está enfrentada a la crisis del tránsito cotidiano de los que la habitamos. No es una ciudad limpia, sino que es una ciudad mosaico de muchas experiencias particulares que permiten comprender y vivir de determinadas formas ese espacio humano y espiritual.

La ciudad se camina, el laboratorio se experimenta. Es necesario, incluso, vagabundear la ciudad, entendiendo el vagabundeo como una práctica espiritual que supone la búsqueda de una mejor situación, ${ }^{15}$ de una realidad escatológica. ${ }^{16}$ Incluso, caminar ya supone el ejercicio de los sentidos: mirar hacia dónde vamos, sentir el bastón en el caso de un ciego, ser capaces de discernir el terreno que pisamos, escuchar, sentir un olor. $Y$, en medio de esas experiencias cotidianas, vamos haciendo experiencia del Dios que nos sale al encuentro en esas identidades peatonales, citadinas, corporales y espirituales.

Estas perspectivas sobre la mística y la espiritualidad hacen que Mendonça (2016) hable de que su propuesta también pueda calificarse de la "espiritualidad del instante" (p. 15) o como "sacramento del instante" (p. 58). Mendonça indica que el instante es el instante concreto, este instante. No es un instante idealizado, sino que tiene que ver con una concreción histórica del instante: "el punto místico de intersección de la historia divina con la historia humana es el instante. No es un instante idealizado o abstracto, sino este instante concreto" (p. 59). Por tanto, la espiritualidad de los sentidos supone el ejercicio de reconocer nuestros instantes y discernirlos, es decir, juzgarlos a la luz del acontecimiento Cristo. Es, incluso, abrirnos a pensar cuáles son los momentos vitales de Cristo (Encarnación, ministerio público, pasión, muerte, resurrección). Por ello, indica Mendonça (2016):

Este minuto preciso en el que estamos, esta hora concreta de nuestras vidas, estos días que nuestro corazón enfrenta con mayor o menor esperanza [...] la mística del instante nos reenvía, así, al interior de una existencia auténtica, nos enseńa a hacernos realmente presentes: a ver en cada fragmento el infinito, a oír el oleaje de la eternidad en cada sonido, a tocar lo impalpable con los gestos más simples, a saborear el espléndido banquete de lo frugal y escaso, a embriagarnos con el perfume de la flor siempre nueva del instante. (pp. 59-61)

Con esto, la mística o espiritualidad del instante, también llamada mística o espiritualidad de los sentidos, va ahondando en una interesante dimensión estética de la realidad, entendiendo por estética el ejercicio de poner en práctica los sentidos. En palabras de Melloni (2019): "no en vano, estética y sentidos provienen de la misma raíz: aisthesin, "sensación". La estética consiste en el arte de afinar los sentidos" (p.

15 Vale la consideración de la obra de Henri David Thoreau Poéticas del caminar. El poeta estadounidense realiza una provocativa concatenación argumentativa que defiende el caminar como una forma de vida auténtica, muy distinta de la cultura civil en la que no se considera al ser humano como parte de la naturaleza, sino solo como miembro de la sociedad. Sostiene Thoreau (2019): "he conocido solo una o dos personas en el curso de mi vida que comprendieran el arte de caminar, esto es, de hacer caminatas. Que tuvieran el talento, por así decirlo de deambular (sauntering); palabra que deriva de manera hermosa de "gente ociosa que vagaba por el campo en la Edad Media pidiendo limosna bajo el pretexto de irse a Tierra Santa (sainte terre) y los niños exclamaban: 'ahí viene un sainte-terrer', un deambulador (saunterrer), un peregrino” (p. 9). Con ello, el auténtico caminante es aquel que posee una dimensión espiritual en su tránsito.

16 La Iglesia misma posee una dimensión de caminante: vamos buscando la ciudad eterna que no conoce de muerte ni de dolor. Esa es la esperanza escatológica: que, mirando a un "más allá" todavía no alcanzado, ya comienza a vivirlo desde el "más acá" de cada uno de nosotros. 
110). Y, en otro momento, esta vez vinculando sentidos y goce o placer (deseo), sostiene: "la percepción de los ojos y de los oídos, la capacidad olfativa de las fosas nasales, la sensibilidad de la piel y el gusto del paladar son el resultado de lentos y sofisticadísimos desarrollos de nuestro organismo, proceso impulsado por la necesidad, pero también por el deseo" (p. 108). Intuiciones similares podemos encontrar en Castelao (2015) quien afirma, por ejemplo, que los artistas son buscadores del Absoluto, en tanto ellos ejercitan lo que él denomina una "razón estética" (p. 143) y que el arte es un modo de percibir lo invisible que está presente en todo lo visible. Castelao (2015), incluso, indica que el artista es un místico, en tanto "él es sensible a la presencia de ese "algo-infinito" (p. 144).

Ahora, es bueno mencionar una salvedad: no es que la flor, no es que la comida o el paisaje sean Dios. Eso sería un panteísmo (todo es Dios y no se reconoce la distancia entre Dios y la creatura). Lo que la espiritualidad de los sentidos nos debe hacer interiorizar es que hay formas a través de las cuales podemos vincularnos con Dios, que la experiencia de Dios está mediada por lo sensible, en tanto nosotros vivimos un mundo sensible. Por ello, el cuerpo es la lengua materna de cada uno y, a su vez, es la lengua que Dios ha querido utilizar para comunicarse con nosotros. La revelación de Dios, la experiencia de Dios, es histórica, sensible, corporal. Pero no es que la historia, lo sensible o el cuerpo sean Dios, sino que son caminos que se abren para hacer esa experiencia. Castelao (2015) utiliza una imagen sugerente: "no podemos percibir el giro del globo terráqueo porque nos falta la distancia para verlo desde fuera. Giramos con la tierra, y por eso no captamos directa e inmediatamente aquello en o que estamos" (p.120). Por esto, es bueno mantener la distancia, la consciencia de la condición de creatura, la consciencia de que nuestro conocimiento es limitado.

\section{Importancia del "volver a"}

Y porque es limitado, Mendonça (2016) habla del volver a trabajar con nuestros sentidos, a darles una profundidad diferente y un sentido que vaya re-educándose. Es necesario emprender este camino en razón de lo que denomina una "atrofia de los sentidos" (p. 19). La atrofia de los sentidos tiene que ver con la falta de desarrollo simbólico-espiritual de los sentidos, no de una complejidad biológico-médica sufrida por ellos. Por ejemplo: signos de la atrofia de los sentidos es solo escuchar lo que a nosotros nos conviene oír; es ver solo lo que ocurre en nuestro pequeño núcleo y no ser capaces de reconocer lo que está aconteciendo más allá de nosotros; es no tener la capacidad de degustar otros sabores vitales y creyentes, conformándonos solo con nuestras experiencias particulares.

Esto, en palabras de Mendonça (2016), y a propósito de la respiración/olfato, hace referencia a lo siguiente: "respirar, vivir, no es solo tomar y expulsar aire, mecánicamente: es existir con, es vivir en estado de amor. Y, de la misma manera, abrazar el misterio es entrar en lo singular, en lo afectivo. Dios es cómplice de la afectividad: omnipotente y frágil; pasible e impasible, trascendente y amoroso; sobrenatural y sensible" (p. 46). Es decir, a través de los sentidos no solo degustamos un sabor, olemos un aroma, vemos un objeto, escuchamos una canción o palpamos una superficie, sino que a través de ellos hacemos una auténtica experiencia de Dios en tanto él es verdaderamente cómplice de lo que nos afecta. Y lo es porque Él, en Jesús de Nazaret, asumió nuestros sentidos y dejó que ellos constituyeran las puertas por medio de las cuales poder vincularse con el mundo. 
Por ello, la atrofia de los sentidos es la negación de la madurez espiritual de los mismos sentidos. En este sentido, el autor indica que la espiritualidad de los sentidos "puede desempeñar un papel transformador crucial" (Mendonça, 2016, p. 20), transformación que ocurre, entre otras cosas, por el "volver a" como figura de asumir y hacer resurgir siempre lo sensitivo-espiritual.

Es desde esta perspectiva que Mendonça (2016) hable de redescubrir el tacto, retornar al gusto, revisitar el olfato, volver a la audición y abrir la visión. Pero, incluso, ahí la racionalidad y la sensibilidad se muestra como limitada, en tanto siempre vamos intentando captar desde otras perspectivas lo que somos y de cómo lo que somos entra en vínculo con Dios. Ante ello, considera que es necesario pensar "un proyecto de espiritualidad" (p. 41). Este proyecto de espiritualidad indica que es necesario

encontrar una nueva hermenéutica, de arriesgar una nueva síntesis, de proponer, partiendo del acto de creer, pero también del acto de vivir, una nueva gramática sapiencial [...] la mística del instante exige que nos tomemos (más) en serio nuestra humanidad como narrativa de Dios que "vive en este mundo". (p. 41)

De este modo, la mística surge como la experiencia de la vida tal cual ella se presenta. No es la vida idealizada, sino que es la vida en ejercicio, con sus experiencias, con sus olores, sabores, tactos, escuchas, aromas, ciudades, calles. Este cambio de perspectiva sobre lo que es la espiritualidad-mística puede constituir una forma sugerente de ir repensando o volviendo a pensar de otro modo. Por ello, Mendonça (2016) indica:

Nos hacen falta maestros no solo de vida interior, sino sencillamente de vida, de una vida total, de una existencia digna de ser vivida. Nos hacen falta cartógrafos y testigos del corazón humano, de sus infinitos y arduos caminos, pero también de nuestra cotidianidad, donde todo es y no es extraordinariamente simple. Necesitamos una nueva gramática que concilie en lo concreto los términos que nuestra cultura concibe como irreconciliables: razón y sensibilidad, eficacia y afectos, individualidad y compromiso social, gestión y compasión, espiritualidad y sentidos, eternidad e instante. (pp. 42-43)

Por tanto, y a partir de los elementos teóricos que hemos ofrecido, creemos conveniente proponer algunas preguntas que permitirán a los lectores continuar reflexionando en torno a la espiritualidad de los sentidos tanto en su lectura personal como en la práctica pastoral o académica:

- ¿Cómo continuar ejercitando la espiritualidad de los sentidos?

- ¿Por qué un tiempo de pandemia necesitaría maestros de vida?

- ¿Cuáles son los cartógrafos que hoy precisamos? ¿Qué pastoral supone el ejercicio espiritual de los cartógrafos de este tiempo?

- ¿Cómo continuar valorando nuestra cotidianidad como espacio de ejercicio de nuestra espiritualidad?

- ¿Cómo animar a nuestras comunidades en el conocimiento e interiorización de la espiritualidad de los sentidos?

\section{Al finalizar}

La propuesta de la espiritualidad de los sentidos de José Tolentino Mendonça representa, a nuestro entender, una sugerente forma de acercarnos a la dimensión corporal de la experiencia interior. Lo que somos en 
el viaje interior lo vamos volviendo concreto en la vivencia de nuestro cuerpo, de los sentimientos, los afectos y, en nuestro caso, de los sentidos. La espiritualidad cristiana es una vivencia de lo integral, en que es todo el ser humano el que hace la experiencia de la fe y de la vivencia concreta de esta. Junto con ello, indicábamos que la comprensión de lo que es el cuerpo está condicionado y situado en relación con el tiempo en el cual especulamos y comprendemos lo que ese mismo cuerpo es. En nuestro tiempo marcado por la pandemia de la covid-19, se hace indispensable volver a recuperar la inteligencia teológica sobre nuestro cuerpo de manera de vivir de forma resignificada la espiritualidad de y desde los sentidos, vivencia marcada por los relatos de lo urbano, de las ciudades y sus tránsitos.

Luego de la lectura de la obra de Mendonça, consideramos fundamental que las comunidades cristianas continúen interiorizando estas propuestas y puedan asumirlas en vistas al trabajo pastoral, catequético, formativo, especulativo y práctico. La espiritualidad de los sentidos de Mendonça nos puede ayudar a proponer pistas para abrazar esos instantes en los cuales hacemos experiencia de Dios. Si la confesión cristiana se fundamenta en un Dios que asumió la corporeidad de todo ser humano, es desde ese cuerpo y desde sus sentidos que podemos vincularnos con el Dios amante de lo humano. Esto, sin duda, es un proyecto de humanización que, en nuestro tiempo, cobra una mayor relevancia.

\section{Referencias}

Amengual, G. (2007). Antropología filosófica. BAC.

Bentué, A. (1986). La opción creyente. Sígueme.

Benzo, M. (1978). Hombre profano-hombre sagrado: Tratado de antropología teológica. Cristiandad.

Bingemer, M. C. (2008). Masculinidad y feminidad: Dos caras del misterio de Jesucristo. Concilium: Revista Internacional de Teología, 326, 49-60.

Boasso, F. (1989). El rostro descubierto del misterio del hombre. Guadalupe.

Canals, S. (2002). El poder de la caricia. Grijalbo.

Canals, S. (2015). Algo resuena en lo profundo: La enfermedad, el sentido y la felicidad. Uqbar.

Castelao, P. (2015). La visión de lo invisible: Contra la banalidad intrascendente. Sal Terrae.

Cardona Ramírez, H., \& Angel, M. (2017). La impronta bíblica de laudato si'. Diálogo a dos voces entre la encíclica y los inicios del génesis. Cuestiones Teológicas, 44(102), 301-346. https://doi.org/10.18566/cueteo.v44n102.a05

De Castro, J. (2006). Para mejorar la vida: Introducción a la psicología de Carl Gustav Jung. Universidad Católica de Chile.

De Certeau, M. (2007). La invención de lo cotidiano. Vol. 1: Artes de hacer. Universidad Iberoamericana.

Espinosa Arce, J. P. (2020, 18 de mayo). Pausa Ignaciana: Las paradojas de las muertes en cuarentena. https://jesuitas. $\mathrm{cl} /$ pausa-ignaciana-las-paradojas-de-las-muertes-en-cuarentena/

Gamarra, S. (2004). Teología espiritual. BAC. 
García, D. (2017). "Ve y hace tú lo mismo" (Lucas 10, 37): Perspectivas sociopolíticas del ágape". En V. Azcuy, D. García y C. Schickendantz (eds.), Lugares e interpelaciones de Dios: Discernir los signos de los tiempos (pp. 315-345). Universidad Alberto Hurtado.

Gelabert Ballester, M. (2006). Jesucristo, revelación del misterio del hombre: Ensayo de antropología teológica. San Esteban.

Gesché, A. (2010). Dios para pensar: El hombre. Sígueme.

López Escamez, J. (2020, 12 de mayo). Sintomas del coronavirus: la razón médica por la que el covid-19 puede hacernos perder el olfato y el gusto. BBC. https://www.bbc.com/mundo/noticias-52632709

López, L. (2019). Corporalidad. En P. d’Ors, R. Galve, R. Pinilla, C. Álvarez Puerto, L. López, R. M. Nogués y L. Ylla (eds.), Itinerarios interiores. Fragmenta.

Maturana, H. R. (2020). Emociones y lenguaje en educación y política. Paidós.

Melloni Ribas, X. (2019). El deseo esencial. Sal Terrae.

Mendonça, J. T. (2016). Hacia una espiritualidad de los sentidos. Fragmenta.

Nolan, A. (2007). Jesús hoy: Una espiritualidad de libertad radical. Sal Terrae.

Nussbaum, M. (2014). Emociones políticas: ¿Por qué el amor es importante para la justicia? Paidós.

Sánchez Rodríguez, F. J. (2006). Nostalgia de lo íntimo. En F. J. Sánchez Rodríguez (ed.), Mistica y sociedad en diálogo (pp. 9-39). Trotta.

Sesböue, B. (2000). Creer: Invitación a la fe católica para las mujeres y los hombres del siglo XXI. San Pablo.

Silva, S. (1985). Antropología teológica. Pontificia Universidad Católica de Chile.

Thoreau, H. D. (2019). Poéticas del caminar. Alquimia.

Torralba, F. (2019). Inteligencia espiritual. Plataforma Actual.

Watt, N. (2006). La fuente de la cordialidad. En F. J. Sánchez Rodríguez (ed.), Mistica y sociedad en diálogo (pp. 78-86). Trotta.

Wicks, J. (1998). Introducción al método teológico. Verbo Divino.

Žižek, S. (2021). Pandemia: el covid-19 estremece al mundo. Té Chai. 